\title{
Synthesis, Characterization and Antitumor Activity of New Organotin(IV) Methoxyethyldithiocarbamate Complexes
}

\author{
NORMAH AWANG ${ }^{1}$, NURUL FARAHANA KAMALUDIN ${ }^{1}$, IBRAHIM BABA ${ }^{3}$, \\ KOK MENG CHAN ${ }^{1}$, NOR FADILAH RAJAB ${ }^{2}$ and ASMAH HAMID ${ }^{2}$
}

\author{
${ }^{1}$ Environmental Health and Industrial Safety Program, Faculty of Health Sciences, \\ Universiti Kebangsaan Malaysia, Jalan Raja Muda Abdul Aziz, 50300 Kuala Lumpur, Malaysia \\ ${ }^{2}$ Biomedical Science Program, Faculty of Health Sciences, Universiti Kebangsaan Malaysia, \\ Jalan Raja Muda Abdul Aziz, 50300 Kuala Lumpur, Malaysia \\ ${ }^{3}$ School of Chemical Sciences and Food Technology, Faculty of Science \& \\ Technology, Universiti Kebangsaan Malaysia, 43600 Bangi Selangor, Malaysia \\ ${ }^{*}$ Corresponding author e-mail: awang_normah@yahoo.com
} http://dx.doi.org/10.13005/ojc/320110

(Received: October 22, 2015; Accepted: March 03, 2016)

\begin{abstract}
Two new organotin(IV) dithiocarbamate complexes of the type $R_{3} S n L$ and $R_{2} S_{n} L_{2}(L=$ methoxyethyldithiocarbamate and $\mathrm{R}=\mathrm{C}_{6} \mathrm{H}_{5}$ or $\mathrm{C}_{4} \mathrm{H}_{9}$ ) were synthesized in good yields. The organotin complexes were suitably characterized by elemental analysis, FT-IR, ${ }^{1} \mathrm{H}$, and ${ }^{13} \mathrm{C}$ NMR spectroscopies. These complexes were prepared in situ. Elemental analysis data (carbon, hydrogen, nitrogen, and sulfur) showed an agreement with the suggested formula structures. The infrared spectra of these complexes showed three important peaks for $v(C=N), v(C=S)$, and $v(S n-S)$ in the region of 1450-1463, 992-994, and 324-326 $\mathrm{cm}^{-1}$ respectively. Data for ${ }^{13} \mathrm{C}$ NMR spectroscopy showed an important peak in the region of $\delta_{c} 197-201 \mathrm{ppm}$ that corresponded to the NCS group. These complexes were evaluated for their in vitro anti proliferative activities against $\mathrm{HL}-60$ cell lines. The results showed that both of these complexes had high cytotoxicities toward $\mathrm{HL}-60$ cell lines with the $\mathrm{IC}_{50}$ values below $1 \mu \mathrm{M}$.
\end{abstract}

Key words: Synthesis, Organotin(IV), Spectroscopy, Dithiocarbamate, Cytotoxicity.

\section{INTRODUCTION}

Dithiocarbamates are sulfur- and nitrogencontaining ligands that display a rich and varied coordination chemistry, thus providing a wide range of transition and main group metal complexes (Hill et al. 1985). These ligands are versatile chelating with diverse applications in industry, agriculture, and medicine (Hulanicki 1967; Coucouvanis 1970). Dithiocarbamates deal with a great interest in inorganic synthesis as they have a number of applications. These ligands have attracted the attention among scientists because of their potential biological activities (Leka et al. 2006). Their metal 
complexes present striking structural features and have diversified applications such as high-pressure lubricants and accelerators used in vulcanization (Beer et al. 2001).

Some dithiocarbamates have also been found to be pharmacologically active, used for the treatment of alcoholism (Jacobsen 1950), and tested in clinical trials for various infections including HIV (Hersh et al. 1991; Kaplan et al. 1989; Lang et al. 1988) and cancers (Dufour et al. 1993; Francis et al. 1993; Verma et al. 1990). The antitumor effects of these dithiocarbamates can in part be attributed to their ability to complex tumor cellular copper, leading to binding to and inhibition of the proteasome and in turn initiating tumor cell-specific apoptosis (Buac et al. 2012). Besides, these dithiocarbamates have also been used in the treatment of bacterial and fungal infections (Menezes et al. 2004).

In view of the wide-range applications of organotin(IV) dithiocarbamate complexes, we report in this article the synthesis and characterization of dibutyltin(IV) and triphenyltin(IV) methoxyethyldithiocarbamate complexes and the cytotoxic study of these complexes to evaluate their potential as anticancer agents.

\section{MATERIALS AND METHODS}

All chemicals and solvents used in this experiment were purchased from Merck Company and used without purification due to their high purity. The melting points were determined in open capillary tubes using an electrothermal 9300 digital melting point apparatus. The percentage compositions of carbon, hydrogen, nitrogen, and sulfur were determined using an elemental analyzer, CHNS-O Model Fison EA1108. Solid state infrared spectra were recorded as potassium bromide discs using a Perkin-Elmer spectrophotometer GX. The ${ }^{1} \mathrm{H}$ and ${ }^{13} \mathrm{C}$ nuclear magnetic resonance spectra were recorded using a BRUKER FT-NMR $600 \mathrm{MHz}$ Cryo-Probe spectrometer with DMSO- $\mathrm{d}_{6} / \mathrm{CDCl}_{3}$ as solvent.

\section{Synthesis of Organotin(IV) Dithiocarbamate Complexes}

Organotin(IV) dithiocarbamate complexes were prepared using a direct reaction between $5 \mathrm{~m}$ $\mathrm{mol}$ of carbon disulfide and $5 \mathrm{mmol}$ of ethanolic solution of methoxyethylamine. The reaction mixture was then stirred for $1 \mathrm{~h}$ at $277 \mathrm{~K}$ temperature and added dropwise to organotin(IV) (dibutyltin(IV) or triphenyltin(IV)) chloride (suitable amount) in 20 $\mathrm{mL}$ of ethanol. The precipitate formed was filtered and washed with cold ethanol and then dried in a desiccator. These complexes were then recrystallized from chloroform.

\section{MTT Cytotoxicity Assay}

The cytotoxicity of the synthesized compounds was screened using a 3-(4,5dimethylthiazol-2-yl)-2,5-diphenyltetrazholium bromide (MTT) assay as described by Mosmann (1983). Briefly, the HL-60 $\left(1 \times 10^{6}\right.$ cells $\left./ \mathrm{mL}\right)$ cells were treated with the synthesized compounds in a series of concentrations in a 96-well plate. Following $24 \mathrm{~h}$ of incubation, $20 \mu \mathrm{L}$ of MTT (Sigma-Aldrich, USA) $(5 \mathrm{mg} / \mathrm{mL}$ in PBS solution) was added into each well while excluding ambient artificial light and further incubated for $4 \mathrm{~h}$. Then, $180 \mu \mathrm{L}$ of supernatant was carefully removed from each well, and 180 $\mu \mathrm{L}$ DMSO (Fisher Scientific, UK) was added to dissolve the formazan crystals formed. After 15 to 20 min of incubation, the absorbance of each well was measured using an ELISA microplate reader (iMark) (Bio-Rad Laboratories, USA) at $570 \mathrm{~nm}$. The graphs were plotted as a percentage of viable cells vs. compound concentrations. The $\mathrm{IC}_{50}$ values were determined based on the plotted graphs where by the $I_{50}$ values represented the reduction of $50 \%$ of the cell population in the treated cells compared to the untreated cells. Doxorubicin hydrochloride was used as a positive control.

\section{RESULTS AND DISCUSSIONS}

\section{Synthesis}

Two new organotin(IV) dithiocarbamate complexes were prepared using an insertion technique (Abdul Muthalib et al. 2011), which is a reaction involving organotin(IV) chloride, methoxy ethylamine, and carbon disulfide at $277 \mathrm{~K}$ in an ethanol solvent to give stable complexes. The scheme for the reaction involved in the synthesis is shown in Figure 1. Both complexes exhibited as a white solid and was stable in air and highly soluble in chloroform. Recrystallization process was done to the complexes using chloroform as a solvent. The resulting solution was slowly evaporated, and colorless crystals of the 
complexes were obtained. The elemental analysis showed that the experimental values were in agreement with the theoretical values based on their chemical formula (see Table 1). The percentage of tin in the complexes was determined using gravimetric analysis.

\section{Infrared Spectroscopy}

The important infrared absorption bands of complexes 1 and 2 are presented in Table 2. Based on the spectral data, each complex exhibited a peak assigned as thioureide band, $\mathrm{n}(\mathrm{C}=\mathrm{N})$ in the region of 1470-1500 cm"1 (Bonati \& Ugo 1967; Sharma et al. 1996). The infrared spectra of the dithiocarbamate complexes showed very in tense absorptions in the region of $1487-1470 \mathrm{~cm}^{\prime 1}$, attributed to thioureide vibration (Honda et al. 1968).

Reaction scheme of complex 1 (dibutyltin)

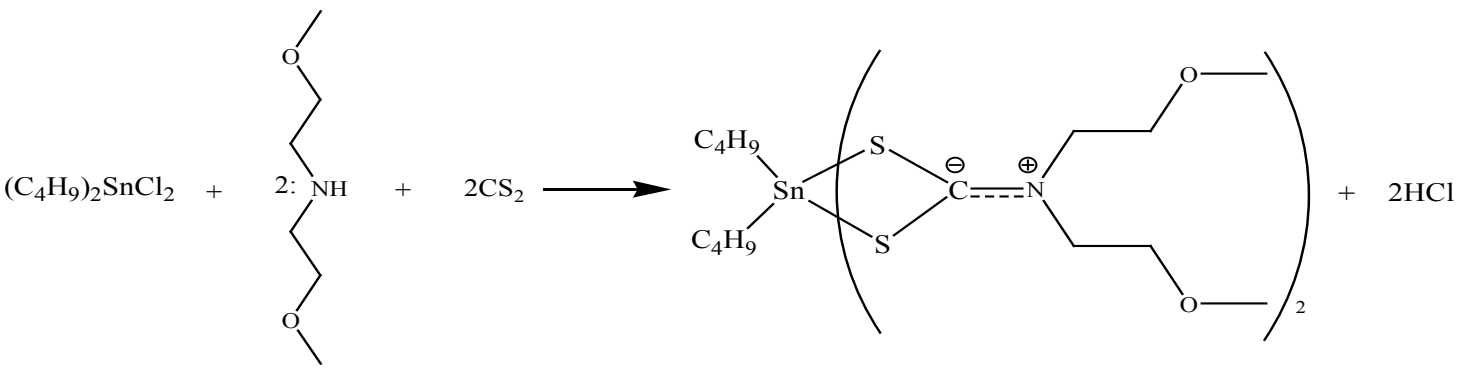

Reaction scheme of complex 2 (triphenyltin)

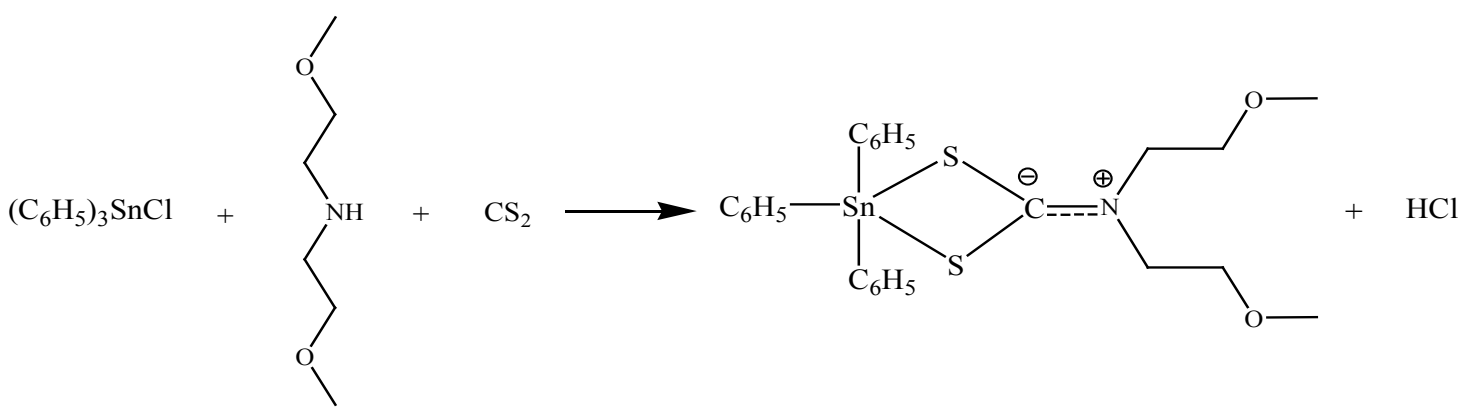

Fig. 1: Reaction scheme of $b$ is(methoxyethy lamine), carbon disulfide, and dibutyltin(IV) dichloride (complex 1) triphenyltin(IV) chloride (complex 2)

Table 1: Physical and elemental analysis data for complexes 1 and 2

\begin{tabular}{ccccccccc}
\hline Complex & $\begin{array}{c}\text { Yield } \\
(\%)\end{array}$ & $\begin{array}{c}\text { Melting } \\
\text { point }\left({ }^{\circ} \mathbf{C}\right)\end{array}$ & \multicolumn{5}{c}{ Elemental analysis \% Found ( Calculated) } \\
\cline { 5 - 8 } & & Carbon & Hydrogen & Nitrogen & Sulfur & Tin \\
\hline \multirow{2}{*}{1} & \multirow{2}{*}{76} & $68-69$ & 41.76 & 6.07 & 4.91 & 19.25 & 27.38 \\
& & & $(40.77)$ & $(7.14)$ & $(4.31)$ & $(19.75)$ & $(28.03)$ \\
& \multirow{2}{*}{89} & $93-94$ & 54.38 & 4.38 & 2.87 & 12.13 & 26.11 \\
& & & $(53.76)$ & $(5.24)$ & $(2.51)$ & $(11.49)$ & $(27.00)$ \\
\hline
\end{tabular}


Furthermore, another important peak observed in these compounds was $\mathrm{n}(\mathrm{Sn}-\mathrm{C})$, and the peaks within the range $544-559 \mathrm{~cm}^{\prime \prime}$ signified the presence the of Sn-C stretching bands for the compounds with phenyl or butyl moiety. The SnSulfur coordination was supported by the presence of medium absorptions in the region of 386-425 $\mathrm{cm}^{-1}$, verifying the bonding of the tin metal with sulfur atom of the methoxy ethyldithiocarbamatelig and (Shahzadi et al. 2006; Santacruz-Juarez et al. 2008).

\section{NMR Spectroscopy}

${ }^{1} \mathrm{H}$ NMR spectra for these complexes were recorded in $\mathrm{CDCl}_{3}$ solution, and tetramethylsilane was used as an internal standard at room temperature. The proton of methoxy group for both complexes exhibited a sharp singlet signal at $\delta_{\mathrm{H}} 3.35 \mathrm{ppm}$ (see Table 3). The protons of ethylene groups, $\mathrm{N}-\mathrm{CH}_{2}$ and $-\mathrm{CH}_{2}$ attached to the nitrogen atom exhibited a triplet signal, respectively, at $\delta_{H} 3.70$ and $\delta_{H} 4.13 \mathrm{ppm}$ for dibutyltin(IV) complex and $\delta_{\mathrm{H}} 3.72$ and $\delta_{\mathrm{H}} 4.13 \mathrm{ppm}$ for triphenyltin(IV) complex.

In the case of the dibutyltin(IV) compound, i.e., complex $\mathbf{1}$, a triplet signal was observed for the methyl protons at $\delta_{\mathrm{H}} 0.94 \mathrm{ppm}$, and three sets of broad signals for the methylene protons were also observed in the ranges of $\delta_{\mathrm{H}} 1.41-1.47,1.88-1.93$, and 2.04-2.07 ppm. The attachment of the butyl group to the electropositive $\mathrm{Sn}$ atom via carbon nuclei would cause a shielding effect, experienced through the carbon chain (Gomez-Ortiz et al. 2002). A complex multiplet was found at $\delta_{\mathrm{H}} 7.27-7.74 \mathrm{ppm}$ in triphenyltin(IV) complex due to the aromatic protons of the phenyl group directly attached to Sn atom (Khan et al. 2013).

Table 2: Infrared spectra data of the organotin(IV) methoxyethyldithiocarbamate complexes

\begin{tabular}{cccccc}
\hline Complex & \multicolumn{5}{c}{ Wavenumber $\left(\mathbf{c m}^{-1}\right)$} \\
& $v$ & $v$ & $v$ & $v$ & $v$ \\
& $(\mathrm{C}-\mathrm{N})$ & $(\mathrm{C}=\mathrm{S})$ & $(\mathrm{C}-\mathrm{H})$ & $(\mathrm{Sn}-\mathrm{C})$ & $(\mathrm{Sn}-\mathrm{S})$ \\
\hline 1 & 1487 & 992 & 2921 & 544 & 386 \\
2 & 1470 & 994 & 2935 & 559 & 425 \\
\hline
\end{tabular}

The important data of ${ }^{13} \mathrm{C}$ NMR of these complexes are depicted in Table 4. The ${ }^{13} \mathrm{C}$ NMR spectra of complexes 1 and $\mathbf{2}$ exhibited signals for the $\mathrm{O}-\mathrm{CH}_{3}$ carbon at the same chemical shift $\left(\delta_{\mathrm{C}} 59.01\right.$ $\mathrm{ppm}$ ). The chemical shift of the butyl carbon atoms attached to the tin atom in complex 1 appeared at

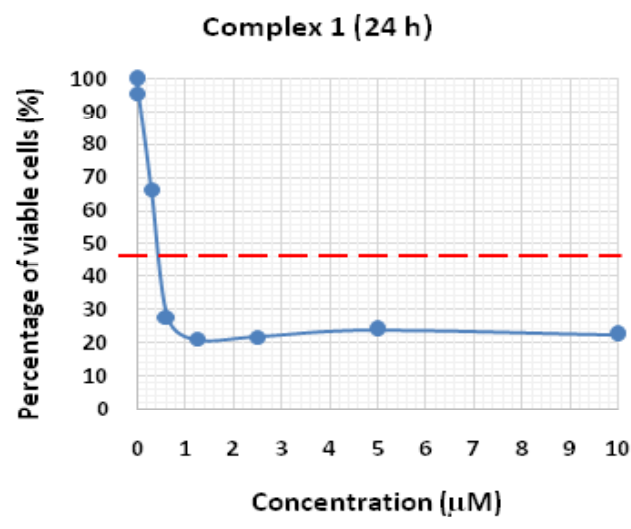

Complex $2(24 \mathrm{~h})$

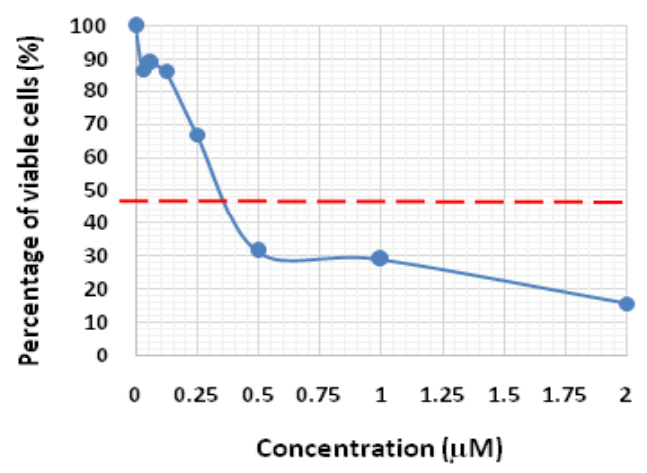

Doxorubicin hydrochloride (24 h)

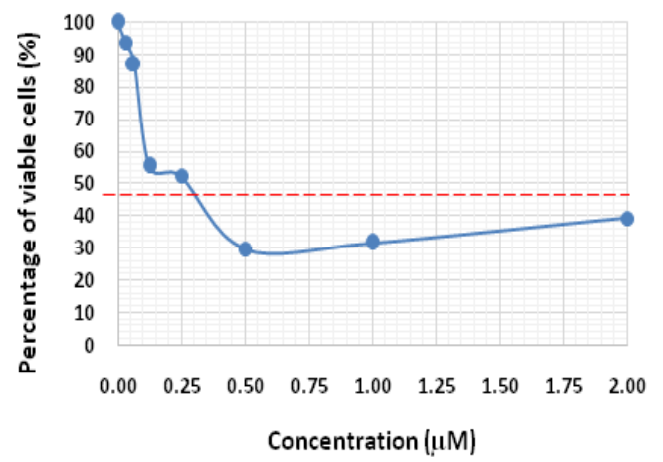

Fig. 2: Graphical representation of the cytotoxic activity of complexes 1 and 2 and doxorubic in against HL-60 cell lines.The red line (----) indicates the $50 \%$ of viable cells population 
Table 3: ${ }^{1} \mathrm{H}$ NMR data of the organotin(IV) methoxyethyldithiocarbamate complexes

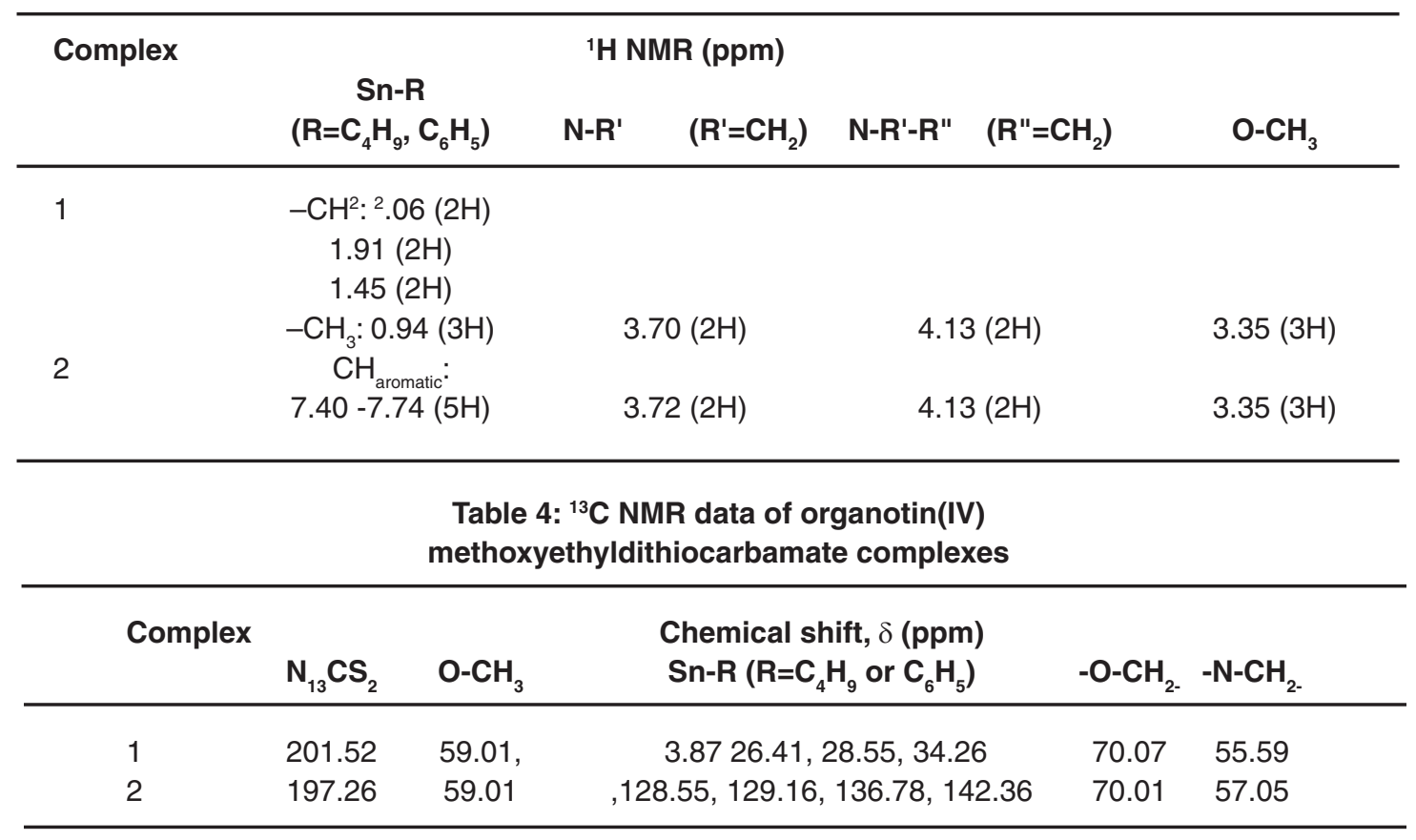

Table 5: $\mathrm{IC}_{50}$ values of the organotin(IV) methoxyethyldithio carbamate compounds on HL-60 cell lines

\begin{tabular}{cc}
\hline Complex & IC50 values $(\boldsymbol{\mu M})$ \\
\hline 1 & 0.40 \\
2 & 0.35 \\
\hline
\end{tabular}

Note: $\mathrm{IC}_{50}(\mathrm{mM})$ is the concentration that shows $50 \%$ inhibition of the cell population. The $\mathrm{IC}_{50}$ of doxorubicin hydrochloride is $0.275 \mu \mathrm{M}$.

$\delta_{\mathrm{C}}$ 13.87-34.26 ppm. The signal at the region $\delta_{\mathrm{C}}$ 128.55-142.36 ppm was assigned to the aromatic carbons attached to the tin atom of complex 2 (Khan et al. 2015). The assignment of ${ }^{13} \mathrm{C}$ signal for the $\mathrm{NCS}_{2}$ group for complexes 1 and 2 appeared at $d_{c} 201.52$ and $d_{c} 197.26$ ppm, respectively, which indicated that the coordination between sulfur and tin atoms was performed (Van Gaal et al. 1979).

\section{In vitro Cytotoxic Activity}

The efficiency of the synthesized dibutyland triphenyltin(IV) complexes as potential antitumor agents were preliminarily tested in vitro against $\mathrm{HL}-60$ cell lines. The results of the in vitro cytotoxic activity of complexes 1 and 2(see Table 5 and Figure 2) against $\mathrm{HL}-60$ cell lines were compared using doxorubicin hydrochloride as a positive control. Previous studies carriedout by our group demonstrated that the organotin (IV) dithiocarbamate complexes are potent to be developed as anticancer agents (Awang et al. 2010; Khan et al. 2014a; Khan et al. 2014 b). The values are expressed asl $\mathrm{C}_{50}$, i.e., the concentration of compound (in $\mu \mathrm{M}$ ) that inhibits a proliferation rate of the tumor cells by $50 \%$ as compared to the untreated cells as a control.

The results signified that the tested organotins induced a concentration-dependent anti proliferative effect toward HL-60 cells upon treatment for $24 \mathrm{~h}$. These two complexes exhibited high antiproliferative effects; thus, this finding was in agree ment with the previous study by Awang et al. (2010). Compared to the value of triphenyltin (IV) complex, the dibutyltin (IV) complex displayed a higher potency against the $\mathrm{HL}-60$ cells, and the $\mathrm{IC}_{50}$ values were on the other hand much lower. Therefore, both of these complexes have the potential to be developed as antitumor agents due to their potent cytotoxiceffect at micromolar concentrations. As these results are 
preliminary, further mechanistic studies on the antitumor activities of these complexes are highly recommended.

\section{CONCLUSION}

The formation of the dibutyltin(IV) and triphenyltin(IV) methoxyethyldithiocarbamate complexes were confirmed via characterization analysis. The micro elemental composition in both complexes were in good percentages and in agreement with the suggested molecular formulas. The presence of the thioureide bands, $n(C=N)$ and the Sn-S stretching frequencies in the complexes indicated the formation of the dithiocarbamate groups and the bonding between the Sn(IV) with the dithiocarbamate ligands, respectively. The formation of dithiocarbamates were further supported by the $\mathrm{NCS}_{2}$ peaks recorded via ${ }^{13} \mathrm{C}$ NMR. The cytotoxicity assay of these complexes showed a high cytotoxic activity on the HL-60 cell lines.Further in vitro and in vivo studies are recommended as the next research stages on these potential complexes.

\section{ACKNOWLEDGEMENT}

This work was supported by the grant FRGS/2/2013/SKK10/UKM/02/1. We gratefully acknowledge the School of Chemical Science and Food Technology, Universiti Kebangsaan Malaysia for providing the essential laboratory facilities. We would also like to thank the laboratory assistants from the Faculty Science and Technology, Universiti Kebangsaan Malaysia for their technical support.

\section{REFERENCES}

1. Abdul Muthalib, A.F., Baba, I., Abdul Aziz, Y.F. \&Samsudin, M.W.. Synthesis and characterization of diphenyltin(IV) dithiocarbamate compounds. The Malaysian Journal of Analytical Sciences,2011,15(1), 106-112.

2. Beer, P.D., Berry, N., Drew, M.G.B., Fox, O.D., Padilla-Tosta, M.E., \&Patell, S.. Selfassembled dithiocarbamate-copper(II) macrocycles for electrochemical anion recognition. Chem. Commun. 2001, 4, 199200.

3. Bonati, F. \&Ugo, R..Organotin(IV) N,NdisubstitutedDithiocarbamates. Journal of Organometallic Chemistry.1967, 10, (2):257268.

4. Coucouvanis, D.. The chemistry of the dithioacid and 1,1-dithiolate complexes. Prog. Inorg. Chem. 1970, 11, 233-371.

5. Dufour P, Lang JM, Giron C, Duclos B, Haehnel P, Jaeck, D, Jung JM \&Oberling F. Sodium dithiocarbamate as adjuvant immunotherapy for high risk breast cancer: a randomizedstudy. Biotherapy.1993, 6, (1) :9-12.

6. P. Francis, M. Markman, T. Hakes, B. Reichman, S. Rubin, W. Jones, J.L. Lewis, J. Curtin, R.Barakat, \& M. Phillips. Diethyldithiocarbamate chemoprotection of carboplatin-induced he matological toxicity.
Journal of Cancer Research and Clinical Oncology. 1993, 119,(6), 360-362.

7. Hill, J.O., Magee, R.J. \&Liesegang, J.. Photoelectron spectroscopy of metal dithiocarbamate, xanthate and dithiophosphate complexes: A review comments on inorganic chemistry. A Journal of Critical Discussion of the Current Literature.1985, 5(1): 1-27.

8. Hulanicki, A..Complexation reactions of dithiocarbamates. Talanta.1967, 14(12): 1371-1392.

9. Leka Z.B, Leovac V.M, Lukic S, Sabo T.J, Trifunovic S.R \& Katalin M.S.. Synthesis and physico-chemical characterization of new dithiocarbamato ligand and its complexes with copper(II), nickel(II) and palladium(II). J. Therm Anal and Cal. 2006, 83.

10. Lang, J. M., Touraine, J. L., Trepo, C.,Choutet, P.,Kirstetter, M., Falkenrodt, A., Herviou, L.,Livrozet, J. M.,Retornaz, G.,\&Touraine, F..Randomised, double-blind, placebocontrolled trial of ditiocarb sodium ('Imuthiol') in human immunodeficiency virus in-fection. Lancet 1988, 332: 702-706.

11. Mosmann, T.. Rapid colorimetric assay for cellular growth and survival: Application to proliferation and cytotoxicity assays. Journal of Immunological Methods 1983, 65: 55-63.

12. Naqeebullah Khan, Yang Farina, Kok Meng Chan, Lo KongMun, Nor Fadilah Rajab \& 
Theng Choon Ooi.. Diorganotin(IV) derivatives of $\mathrm{N}$-Methyl p-fluorobenzohydroxamic Acid; preparation, spectral characterization, X-ray Diffraction Studies and antitumor activity. Molecules.2013, 18: 8696-8711.

13. Naqeebullah Khan, Yang Farina, Lo Kong Mun, Nor Fadilah Rajab,\& Normah Awang. a. Triorganotin(IV) complexes with o-substituted arylhydroxamates: Synthesis, spectroscopic characterization, $\mathrm{X}$-ray structures and in vitro cytotoxic activities.Journal of Organometallic Chemistry.2014,763-764: 26-33.

14. Naqeebullah Khan, Yang Farina, Lo Kong Mun, Nor Fadilah Rajab \&NormahAwang. Syntheses, characterization, $\mathrm{X}$-ray diffraction studies and in vitro antitumor activities of diorganotin(IV) derivatives of bis(psubstituted-N-methylbenzylaminedithiocarb amates). Polyhedron. 2015,85: 754-760.

15. Normah Awang, Ibrahim Baba, Nor Syaidatul Akmal Mohd Yousof, \& Nurul Farahana Kamaludin .Synthesis and characterization of Organotin(IV) $N$-Benzyl$\mathrm{N}$-Isopropyldithiocarbamate Compounds: Cytotoxic Assay on Human Hepatocarcinoma Cells (HepG2). American Journal of Applied Sciences.2010, 7(8): 1047-1052.

16. Pellerito, C., Nagy, L., Pellerito, L. \&Szorcsik, A. Biological activity studies on organotin(IV) $)^{\text {n+ }}$ complexes and parent compounds. Journal of Organometallic Chemistry.2006,691(8):17331747.
17. Santacruz-Juarez, E., Cruz-Huerta, J., Hernandez-Ahuactzi, I.F., Reyes-Martinez, R., Tlahuext,H., Morales-Rojas, H., \& Hopfl. H..24and 26-membered macrocyclicdiorganotin(IV) bis-dithiocarbamate complexes with $\mathrm{N}, \mathrm{N}$ 'disubstituted 1,3- and 1,4-bis(aminomethyl) benzene and 1,1'-bis(aminomethyl)ferrocene as spacer groups. Inorg. Chem. 2008,47(21): 9804-9812.

18. Sharma, J., Singh, Y., Bohra, R., \& Rai, A.K.. Synthesis and spectral studies of diorganotin heterocyclic dithiocarbamate complexes: The crystal structure of $\left(\mathrm{CH}_{3}\right)_{2} \mathrm{Sn}\left[\left(\mathrm{S}_{2} \mathrm{CNCH}_{2} \mathrm{CH}_{2} \mathrm{C}\right.\right.$ $\left.\left.\mathrm{H}_{2} \mathrm{CH}_{2} \mathrm{CH}_{2}\right)\right]_{2}$. Polyhedron.1996, 15(7): 10971102.

19. Shahzadi, S., Ali, S., Bhatti, M. H.,Fettouhi, M. \&Athar, M..Chloro-diorganotin(IV) complexes of 4-methyl-1-piperidine carbodithioic acid: Synthesis, X-ray crystal structures,spectral properties and antimicrobial studies. Journal of Organometallic Chemistry. 2006,691(8): 1797-1802.

20. Van Gaal, H.L.M., Dieskeld, J.W., Pijpers, F.W. \& Van Der Linden, J.G.M. ${ }^{13} \mathrm{C}$ NMR spectra of dithiocarbamates.Chemical shifts, carbonnitrogen stretching vibration frequencies, and $ð$ bonding in the $\mathrm{NCS}_{2}$ fragment. Inorganic Chemistry. 1979, 18(11): 3251-3260.

21. Verma, S., Stewart, D.J., Maroun, J.A. \& Nair, R.C..A randomized phase II study of cisplatin alone versus cisplatin plus disulfiram.American Journal of Clinical Oncology.1990,13:119-124. 